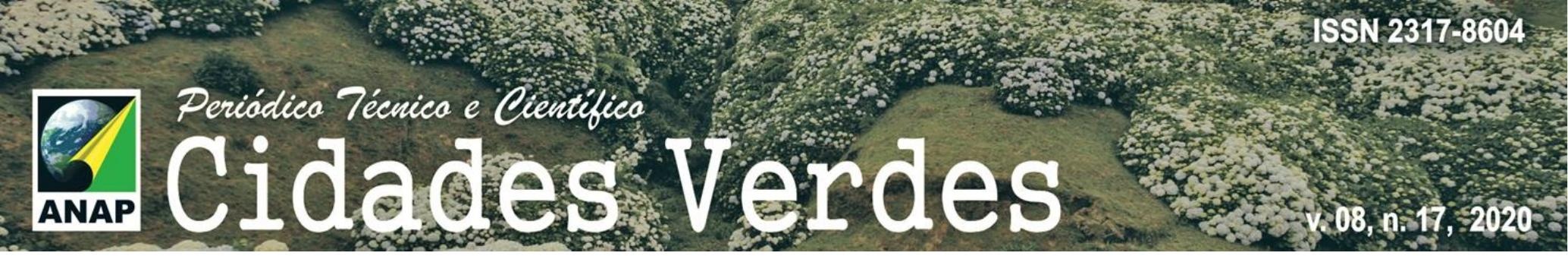

\title{
Parque Estadual do Utinga: pertencimento, pressões antropogênicas e mudanças socioespaciais em Belém-Pará ${ }^{1}$
}

Utinga State Park: belonging, anthropogenic pressures and socio-space changes, Belém-Pará

Parque Estatal de Utinga: pertenencia, presiones antropogénicas y cambios socio-espaciales, Belém-Pará

Jorge Sales dos Santos

Graduando, Universidade Federal do Pará, Brasil

Salesjorge20@gmail.com

Aelton Dias Costa

Graduando, Universidade Federal do Pará, Brasil. aeltondcosta@gmail.com

Rita Denize de Oliveira

Professora Doutora, Universidade Federal do Pará, Brasil.

\footnotetext{
${ }^{1}$ Artigo proposto pelo primeiro autor como requisito parcial para trabalho de Conclusão do Curso de Bacharelado em Geografia, da Universidade Federal do Pará e parte dos Resultados do Grupo de Estudo em Paisagem, Patrimonio Natural e Geodiversidade, da Faculdade de Geografia e Cartografia, da UFPA.
} 


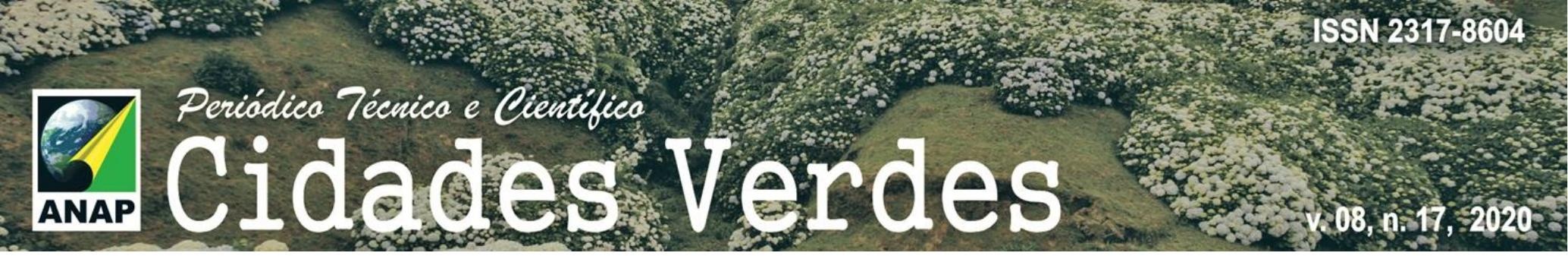

Resumo: O Parque Estadual do Utinga é uma Unidade de conservação de proteção integral que abrange os municípios de Belém e Ananindeua. Com uma área de 1.393,088 hectares. A presença do Parque está relacionada diretamente ao abastecimento da água de Belém, manutenção da rica biodiversidade, e outros serviços ambientais, apresentando-se como área de recreação e lazer. $O$ presente trabalho visa identificar e compreender os processos que acarretaram em mudanças no processo e nas estruturas do Parque Estadual do Utinga (PEUt). A metodologia da pesquisa se realizou a partir de um levantamento da literatura, análise multitemporal imagens de satélites através de softwares como ArcGis; visita in loco coleta de relatos orais e registro fotográfico. Vista que, atualmente a relação dos morados com o parque é voltado para o viés de localização, a maioria dos entrevistados não frequentam mais o parque devido a readequação do mesmo, voltado para atividades de pessoas com o maior poder aquisitivo.

Palavras-chave: Unidade de conservação, Urbano, Lugar; Exclusão Social.

ABSTRACT: Utinga State Park is an integral protection conservation unit covering the municipalities of Belém and Ananindeua. With an area of 1,393.088 hectares. The Park's presence is directly related to Belem's water supply, maintenance of rich biodiversity, and other environmental services, presenting itself as a recreation and leisure area. This paper aims to survey the history of the creation of the Park, identify the actors responsible for the spatial transformations in the Park area and, especially in its surroundings, which covers the Curió-Utinga neighborhood. The research methodology was based on a literature review, multitemporal analysis of satellite images, on-site oral reports collection and photographic record

Keywords: Conservation Unit, Urban, Place; Social Exclusion.

Resumen: El Parque Estatal de Utinga es una unidad de conservación de protección integral que cubre los municipios de Belém y Ananindeua. Con una superficie de 1.393.088 hectáreas. La presencia del parque está directamente relacionada con el suministro de agua de Belem, el mantenimiento de una rica biodiversidad y otros servicios ambientales, presentándose como un área de recreación y ocio. Este documento tiene como objetivo identificar y comprender los procesos que condujeron a cambios en el proceso y las estructuras del Parque Estatal de Utinga (PEUt). La metodología de investigación se basó en una revisión de literatura, análisis multitemporal de imágenes satelitales através de software como ArcGis; visita in situ colección de informes orales y registro fotográfico. Dado que la relación entre las viviendas y el parque se centra actualmente en el sesgo de ubicación, la mayoría de los encuestados ya no asisten al parque debido a su reajuste, dirigido a actividades de personas con el mayor poder adquisitivo.

Palabras clave: Unidad de Conservación, Urbana, Lugar, Exclusion social 


\section{INTRODUÇÃO}

A partir da década de 1970 inicia no âmbito mundial uma série de discussões sobre o modelo de sociedade que se encontravam, principalmente no que se diz respeito às questões ambientais, diante das evidencias da poluição e degradação dos rios, mares, ar e florestas por todo o globo, levou-se as discussões internacionais à conferencia de Estocolmo em 1972, impulsionado o movimento ambientalista e assim, pressionando Os países detetores das técnicas de maneira desigual (SANTOS, 2004) e do modo de (re)produção capitalista que formam o leque dos principais poluidores.

Nesse mesmo sentido a Conferência das Nações Unidas sobre Meio Ambiente e Desenvolvimento CNUMAD ocorrida no Rio de Janeira em 1992, promovendo uma serie de políticas públicas em torno das questões climáticas e de qualidade de vida nas cidades. Assim a política dos parques urbanos ganha força nas capitais do Brasil. (GOMES, 2014) debate sobre a criação de Parques Urbanos no Brasil, revelando-nos a ligação da criação dos parques com o setor imobiliário e a mercantilização da natureza aliado ao discurso de desenvolvimento sustentável, demostrando várias críticas ao termo, e sua contradição por tentar conciliar a acumulação do capital a conservação ambiental.

Antes disso, na década de 1970 foram criados mais de trinta parques em Curitiba-PR (RECHIA, 2003), vinte e quatro em São Paulo-SP (BURGOS, 2003), sete em Salvador - BA (SERPA, 2007) e quinze em Ribeirão Preto - SP (GOMES, 2009). Em 2000 foi elaborado o Sistema Nacional de Unidades de Conservação - SNUC como fruto das políticas ambientais no Brasil.

Em Belém em 1993 é criado a APA - áreas de proteção ambiental e o parque ambiental de Belém, em 2000 em nível nacional é elaborado o sistema nacional das unidades de conservação (SINUC) com isso o parque ambiental de Belém começou a seguir as novas regras do SINUC, em 2008 o parque ambiental de Belém passa a ser dominado Parque Estadual do Utinga e assim, elaborado o plano de manejo do parque;

O Parque Estadual do Utinga (PEUt) está inserido em uma área considerada periférica de Belém, onde a expansão urbana segue a logica de ocupação de áreas protegidas e a maior parte da de sua extensão territorial está localizada no bairro como o mesmo nome "Curió Utinga", dessa maneira a pressão antropogênica no entorno do PEUt e sua UC deram origem a novas dinâmicas e novos atores.

O desafio desta pesquisa é compreender os processos que acarretaram em mudanças no uso e nas estruturas do Parque Estadual do Utinga, assim como a relação do parque com seu entorno tendo como foco o bairro do Curió-Utinga em Belém, a problemática desse artigo surge através de intensas divulgações do parque, apresentado como cartão-postal da cidade, com as seguintes questões: quais as relações dos moradores com o parque? As mudanças estruturais e funcionais do parque mudam essas relações? Se mudam, para quais perspectivas?

A Pesquisa foi desenvolvida em Belém, em uma área de preservação ambiental, historicamente ligada ao abastecimento de água na Região Metropolitana de Belém- RMB, ocorrendo intensos processos de desenvolvimento dos setores que atuam diretamente nesse potencial hídrico. Os itens que abordados neste artigo são: O contexto Histórico da criação do Parque e a Companhia de Águas do Grão-Pará; novas funcionalidades do Parque, formação do Bairro do curió-Utinga e as pressões socioespaciais no entorno do Parque Estadual do Utinga. 


\section{OBJETIVOS}

\subsection{OBJETIVO GERAL}

Identificar mudanças nas estruturas físicas e de funcionamento do Parque Estadual do Utinga (PEUt).

\subsection{OBJETIVOS ESPECÍFICOS}

Compreender a relação dos moradores do entorno com o Parque Estadual do Utinga;

Identificar as mudanças estruturais e funcionais do parque e no que acarreta na vida da população do entorno;

Caracterizar a pressão antropogênica ocorrida no entorno do parque e identificar quais os atores envolvidos nesse processo.

\section{METODOLOGIA DA PESQUISA}

\section{1- LOCALIZAÇÃO DA ÁREA DE ESTUDO}

O Parque Estadual do Utinga- PEUt está localizado na Região Metropolitana de Belém, Nordeste do Estado, em áreas dos municípios de Belém e Ananindeua, abrangendo os bairros de Curió-Utinga, Souza, Castanheira, Guanabara e Águas Lindas, com a sede localizada na Av. João Paulo II, s/ ${ }^{\circ}$, bairro do Curió-Utinga (Figura 01).

Figura 01: Localização da área de Estudo

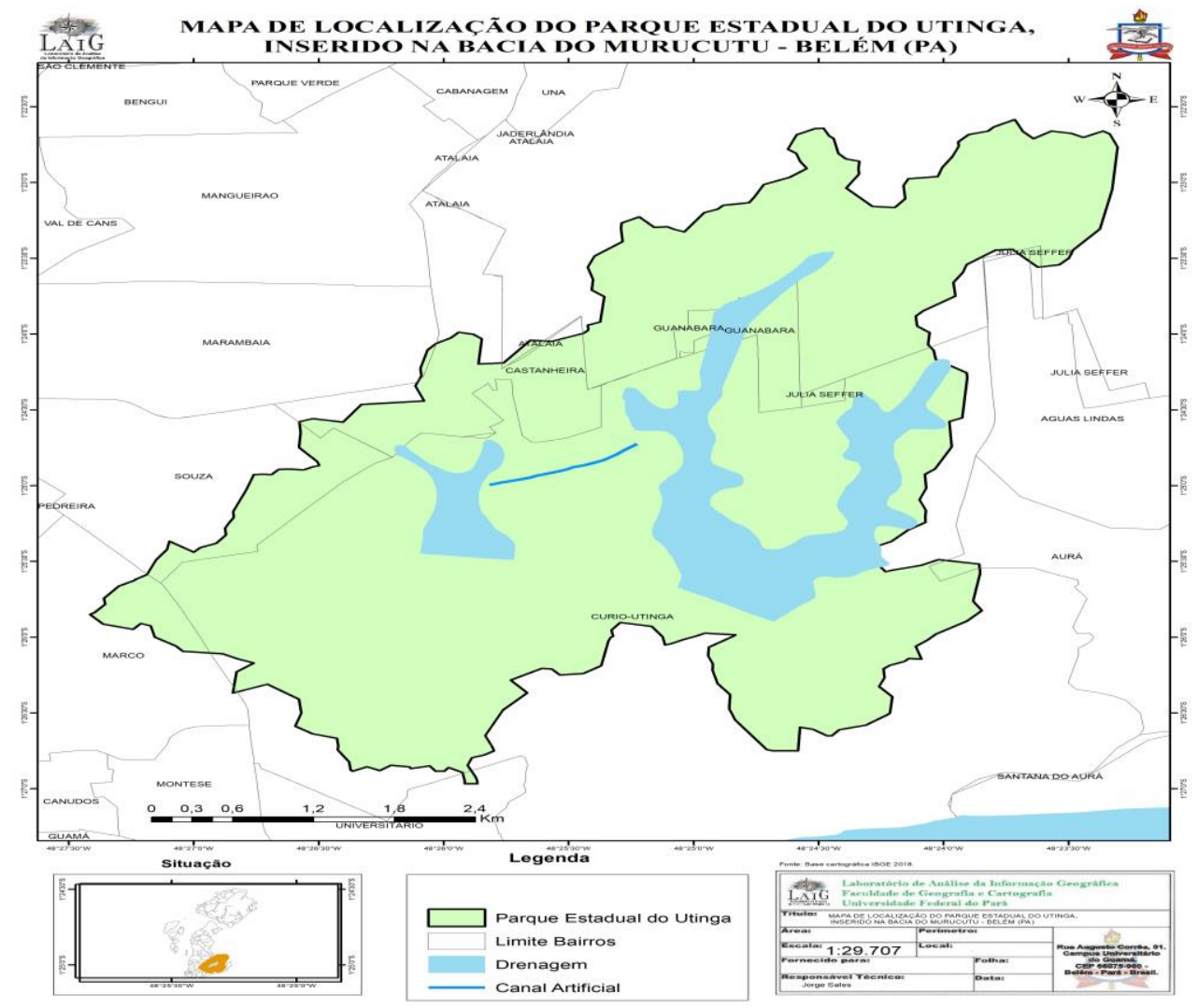

Fonte: SALES. 2019. 


\section{2- ROTEIRO METODOLÓGICO}

A metodologia de trabalho foi desenvolvida da seguinte maneira, com levantamento da literatura especializada no sentido de aproximar aspectos ambientais de uma geografia humanista, por meio do conceito de lugar (TUAN, 1983; 2012) conjugado a noção de patrimônio natural (SCIFONI, 2006; IPHAN, 2016; PEREIRA; 2018). A evolução do uso do solo na parte foi realizada a partir de levantamento de material bibliográfico em sites especializados, como Scielo e Plataforma Sucupira, além de pesquisa no Google Acadêmico e, por meio análise de imagens de satélite Landsat nas bandas 3,4, e 5 para identificar as dinâmicas envolvidas no processo de formação e ampliação do Parque no software ArcGis, e as repercussões sob a população de seu entorno. Utilização do programa Google Earth para delimitar a expansão do parque e sua relação com o entorno, para isso foram selecionados os anos 2005; 2009; 2015 e 2019.

A coleta de relatos e a aplicação de questionários ocorreu por meio de entrevistas formais e informais abordando assuntos do interesse da pesquisa como a dinâmica entre os moradores e o parque bem como a relação com a central de abastecimento de água de Belém., na etapa de trabalho de campo, na área interna e externa do Parque afim de identificar sua infraestrutura, os aspectos físicos e ambientais e os conflitos socioeconômicos locais (Figura 02). Para delimitar os locais de entrevistas se deu estudo da área do entorno e durante as entrevistas a marcação de pontos de localização se deu através do uso do Sistema de Posicionamento Global (GPS)

Figura 02: Pontos de identificação de aplicação de questionários e coleta de relatos.

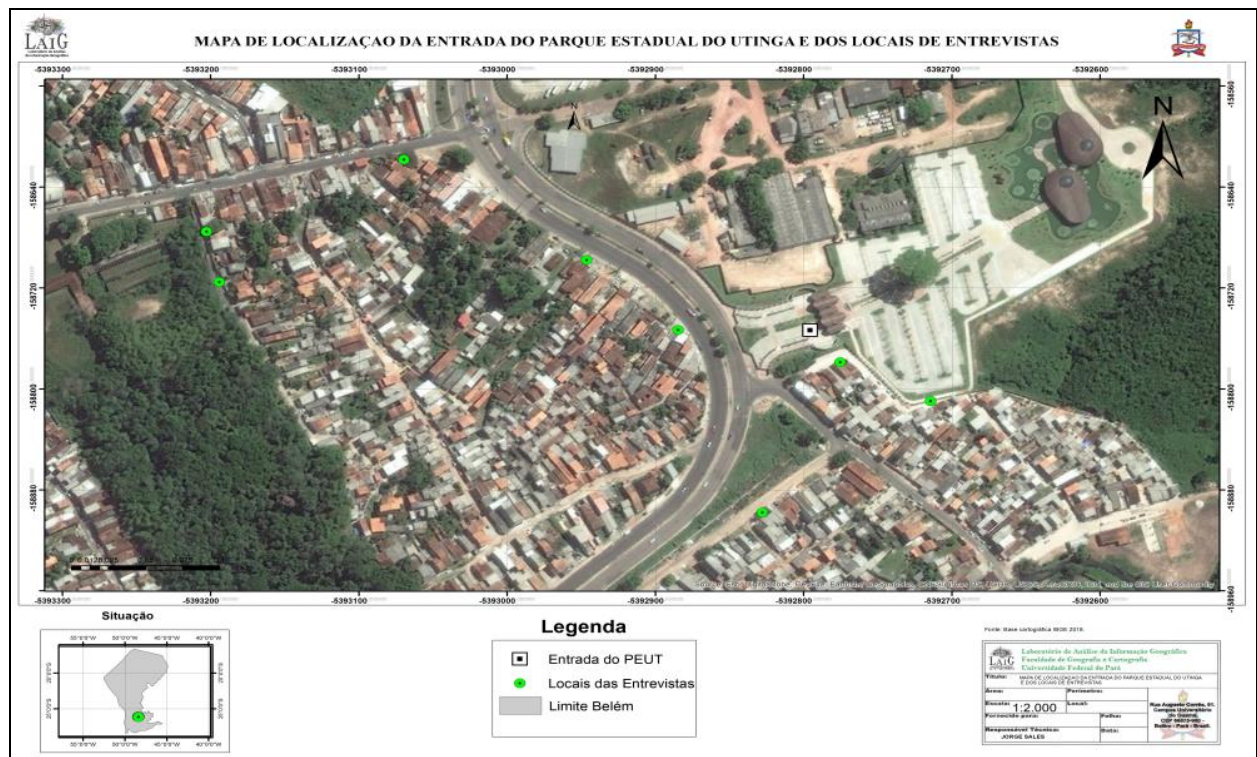

Fonte: Google Earth. Elaboração: SALES. 2019. 


\section{RESULTADOS E DISCUSSÕES}

\section{1- CONTEXTO HISTÓRICO DA CRIAÇÃO DO PARQUE E A COMPANHIA DE ÁGUAS DO GRÃO-PARÁ.}

No final do século XIX começa a ser fomentado na cidade de Belém a canalização da das águas. (ALMEIDA, 2010) que explica que neste momento havia uma necessidade de modernização urbanística, haja vista as péssimas condições relatadas pela autora em seu trabalho.

A canalização da água rumo às residências e prédios em geral, mesmo que morosamente, ganhava o tom de naturalização, ou seja, para muitos dentre os que viviam em Belém, a recorrência ao líquido essencial à vida, assim como o seu processo de esgotamento, também precisavam adequar-se aos ditames do progresso, tal como se fosse uma lei de evolução da vida humana. (ALMEIDA, 2010; p. 142)

Em função da questão fez-se necessário a delegação de uma "companhia" que ficasse responsável pela elaboração e manutenção da distribuição das águas assim com seu esgotamento, esta tarefa foi dada a companhia de águas do Grão-Pará, criada em 1880. A partir da fundação da companhia das águas procurou-se através de estudos técnicos os mananciais que serviriam como fontes de extração das águas que abasteceriam a cidade, escolheu-se então o córrego do Utinga tendo como mananciais Bossuaquara e Antão, mais tarde denominados Bolonha e Água Preta.

Um dos principais critérios utilizados para instalação foi a presença de mata ao redor dos mananciais já que havia a preocupação de que os mananciais estivessem livres da contaminação ocorrida nos espaços urbanos, em função disto foi desapropriado os terrenos que rodeavam os mananciais para a preservação dos mesmos, essa foi a primeira ação pública que delimitou a área em questão. Segundo (CRUZ, 1944) a área destinada a preservação era de 1.486,202 $\mathrm{m}^{2}$ e (ALMEIDA, 2010) explica as razões dessa escolha.

\footnotetext{
Além das considerações que mencionei, a boa qualidade também estava relacionada à conservação das matas próximas aos mananciais. Em vista disso, era preciso estabelecer os limites das referidas áreas, coibir a derrubada da vegetação, evitar a proximidade dos moradores com as nascentes, de modo a afastar os riscos das contaminações, ou seja, era imprescindivel "conservar" as matas. (ALMEIDA, 2010 p. 150).
}

Nesse sentido (ALMEIDA, 2010) explica os trabalhos realizados pela companhia afim de levar os encanamentos até as casas dos moradores, produzindo assim várias plantas e projetos de engenharia, além de compras de equipamentos, outra importante observação é a mão de obra utilizada na instalação do empreendimento.

A companhia de início não alcançará os resultados esperados tendo como primeira construção a caixa d'agua localizada no bairro de São Braz, não atendendo os moradores em sua maioria, vindo seu serviço a ser mais abrangente sendo desapropriada em 1893.

A extração ou utilização dos lagos Bolonha e Água Preta remetem ao final do século XIX, a princípio os lagos naturais eram utilizados por parte da população, a reserva foi criada para proteger os mananciais, neste período estava em construção a Estrada de Ferro Belém - Bragança, uma obra de 


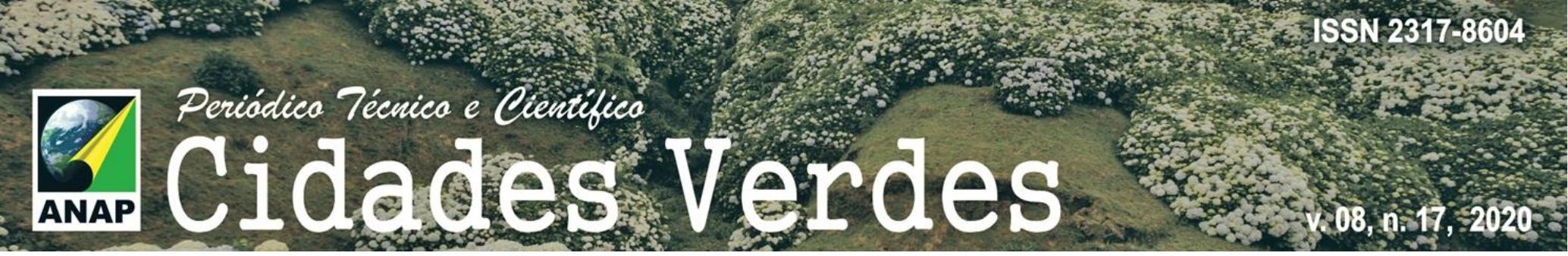

grande importância que atraiu os primeiros moradores a partir do Mercado de São Braz onde havia uma grande caixa d'água da Companhia de Águas do Grão-Pará (ALMEIDA, 2010) .

Percebe-se o processo da primeira delimitação e concluir que ela está intimamente ligada a preservação dos mananciais, dessa forma identificar o uso da área como estratégica para o abastecimento de agua da cidade, tendo como principal gestor a companhia de aguas, inicialmente empreendimento privado com apoio público, e o estado que passa a gerir totalmente a companhia a partir de 1893, e portanto, a área destinada a preservação dos mananciais. A partir desse momento ocorreram várias modificações e denominações como poderemos ver no quadro 01.

Em função da expansão urbana da cidade de Belém e aumento da demanda de água potável, foi necessária uma obra de intervenção desviando parte das águas do rio Guamá para os lagos Bolonha e Água Preta, aumentando sua capacidade de reserva para abastecer a cidade, sendo a primeira grande intervenção antrópica da "Companhia de Águas" ou Companhia de Saneamento do Pará COSANPA. (UTINGA,2013).

Quadro 01: Mudanças na denominação da companhia das águas.

\begin{tabular}{|c|c|c|}
\hline Denominação & Governador & Decreto \\
\hline $\begin{array}{c}\text { Inspetoria das Águas de Belém em } \\
\text { substituição da Companhia das Águas } \\
\text { do Grão-Pará. }\end{array}$ & Lauro Sodré & no 104 de 6 de setembro de 1895 \\
\hline $\begin{array}{l}\text { Extingue-se a Inspetoria das Águas } \\
\text { criando com as mesmas } \\
\text { prerrogativas, a Diretoria dos } \\
\text { Trabalhos Públicos. }\end{array}$ & Paes de Carvalho & no 663 de 21 de março de 1899 \\
\hline $\begin{array}{c}\text { Nova organização ao serviço de água } \\
\text { de Belém. Extingue a Diretoria dos } \\
\text { Trabalhos Públicos e cria a Diretoria } \\
\text { do Serviço de Águas }\end{array}$ & Augusto Monte Negro & no 1015 de 14 de maio de 1901 \\
\hline $\begin{array}{c}\text { Transformou-se em Serviço de Águas } \\
\text { a antiga Diretoria do Serviço de } \\
\text { Águas. }\end{array}$ & José Carneiro da Gama Malcher & no 3621 de 4 de dezembro de 1940 \\
\hline $\begin{array}{l}\text { Nova denominação ao Serviço de } \\
\text { Água, que passou a chamar-se } \\
\text { Departamento Estadual de Água. }\end{array}$ & Octávio Meira & no 4976 de 28 de fevereiro 1946 \\
\hline $\begin{array}{c}\text { Extingue-se o Departamento } \\
\text { Estadual de Água e cria o } \\
\text { Departamento de Águas e Esgotos. }\end{array}$ & Aurélio do Carmo & Decreto não encontrado (ano 1962) \\
\hline $\begin{array}{l}\text { Substitui-se o Departamento de } \\
\text { Águas e Esgotos, pela Companhia de } \\
\text { Saneamento do Pará - COSANPA }\end{array}$ & Alacid da Silva Nunes, & $\begin{array}{l}\text { Lei no } 4336 \text { de } 21 \text { de dezembro de } \\
\qquad 1970\end{array}$ \\
\hline
\end{tabular}

Fonte: CASANPA, ADAPTADO.

Percebe-se a intima relação da área dos mananciais com a distribuição de água para a região metropolitana de Belém (RMB), abastecendo hoje mais de 60\% da mesma (Utinga 2013). No próximo tópico cuidaremos das mudanças ocorridas na funcionalidade do parque desde sua efetiva criação em 1993 até os dias atuais. 


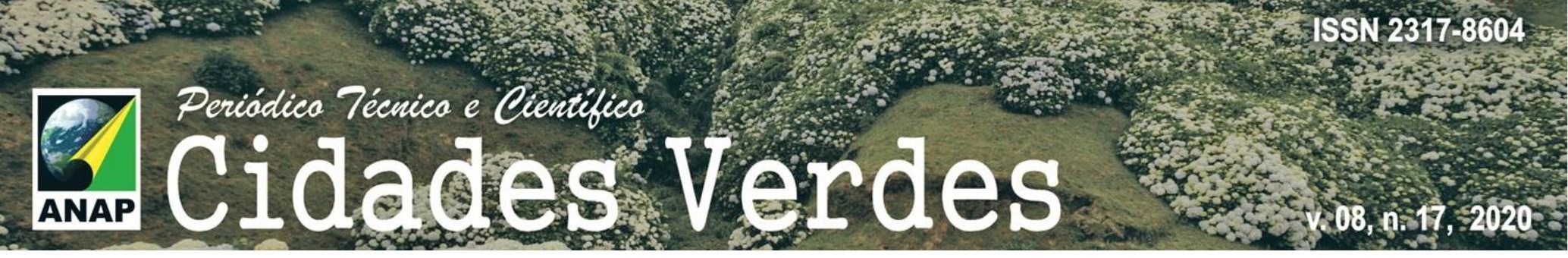

\section{2- NOVAS FUNCIONALIDADES}

Em 1993 foi criado o parque ecológico com o nome de Parque ambiental de Belém, desta vez pretendendo mais que proteger os mananciais, mas ter uma amostra do ecossistema amazônico preservado dentro da cidade através do Decreto № 1.552, de 03 de maio de 1993.

Este decreto foi estabelecido após o Estudo para a Proteção Ambiental dos Mananciais do Utinga e Áreas Adjacentes e do Estudo Ambiental do Parque Estadual do Utinga como podemos observar no Plano de manejo do PEUt, 2013. A partir do decreto a área ganha novas atribuições como podemos acompanhar nos objetivos destinados ao parque no decreto № 1,557 de 1993.

Art. 3ㅇ - O Parque Ambiental de Belém tem por objetivos:

I - Propiciar um espaço de lazer para a comunidade, bem como possibilitar o desenvolvimento de atividades científicas, culturais, educativas, turísticas e recreativas;

II - Assegurar a potabilidade da água através do manejo dos mananciais e da recuperação das áreas degradadas;

III - Ampliar a vida útil dos lagos Bolonha e Água Preta;

IV - Preservar os animais silvestres que se refugiam no local devido a expansão das áreas urbanas circunvizinhas;

V - Assegurar a integridade das florestas e demais formas de vegetação de preservação permanente existentes na área, de acordo com o estabelecido no artigo 2o da Lei Federal no 4.771, de 15 de setembro de 1965, cuja remoção é vedada, com vistas a contribuir na consecução de um índice minimo de cobertura florestal na Região Metropolitana Belém;

VI - Conservar amostras representativas da biodiversidade paraense, constituindo um banco genético em condições de fornecer propágulos para projetos de arborização e reflorestamentos ecológicos, bem como para pesquisas científicas;

VII - Proteger a paisagem;

VIII - Assegurar o convívio da população humana com outras formas de vida vegetal e animal;

IX - Valorizar os municípios de Belém e Ananindeua permitindo o desenvolvimento do turismo;

$X$ - Promover a manutenção das condições ambientais proporcionadas pela vegetação, resultando em benefícios para a melhoria da qualidade de vida da população. (Decreto № 1,557 de 1993).

A partir das mudanças funcionais da área novas intencionalidades no que diz respeito ao manejo e tratamento da mesma, essa ressignificação permite a presença de novos agentes do estado como o a Secretaria de Meio Ambiente e a guarda florestal (UTINGA 2013). Em 2000 é criado o sistema nacional de unidades de conservação-SNUC através da LEI № 9.985, de 18 de julho de 2000. Estabelecendo normas para as unidades de conservação de todo país. Afim de se adequar ao SNUC em 2008 o parque passa a ser denominado de Parque Estadual do Utinga através do decreto $\mathrm{N}^{\circ}$ 1.330, de 2 de outubro de 2008.

O decreto determina ainda que a gestão do parque será gerida por uma comissão, englobando os principais agentes participantes do parque sob a liderança da Secretaria do Meio Ambiente e Sustentabilidade-SEMAS, para isso deverá ser elaborado o plano de manejo do parque, tal plano foi reelaborado pela última vez segundo costa a pesquisa em 2013 (UTINGA 2013). A preocupação dessa pesquisa aloca-se neste último momento, procurando assim compreender as modificações ocorridas, 


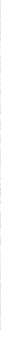

sobretudo no que diz respeito a relação dos moradores encontrados nos arredores do parque, mais especificamente do bairro curió-Utinga. Este bairro ganha importância estratégica de cossa pesquisa por nele estar localizado o oficial e principal acesso ao parque.

\section{3 - FORMAÇÃO DO BAIRRO DO CURIÓ-UTINGA}

Dentre os fatores que norteiam a temática ambiental, a questão antrópica nas áreas de preservação ganha destaque devido sua dinâmica progressiva de crescimento e consequentemente interferindo no meio que abrangem os fatores bióticos e abióticos. Entretanto, acerca do olhar da população que reside dentro e nos arredores das áreas de preservação ambiental, têm-se outra perspectiva, na qual estão inseridos os fatores políticos e sociais que interferem diretamente na dinâmica migratória da população no espaço.

As UCs brasileiras foram sendo implantadas em um contexto onde a ação cotidiana das instituições públicas colocou seus agentes em situação de confronto com os moradores das áreas colocadas sob proteção legal. Para Ferreira (2004), as propostas de conservação formulada em gabinetes, debatida e referendada muitas vezes em fóruns internacionais, no momento de serem implementadas acabaram se tornando altamente politizadas, mobilizando diversos atores em torno de diversas arenas; outros tiveram que rever posições e conceitos e, principalmente os moradores, em sua maioria sem uma prévia experiência importante de participação política, foram repentina e inusitadamente investidos na condição de atores

O bairro curió-Utinga localizasse entre a avenida Almirante Barroso e a avenida João Paulo II, segundo pesquisa feita para o plano de manejo do PEUt 2013 o bairro pertencia ao bairro do Marco, apresentando-se com uma área arborizada e que chamava a atenção por ser lar de uma ave muito apreciada, popularmente conhecida pelo nome de curió, daí o nome curió-Utinga.

Algumas pessoas segundo a pesquisa plano de manejo do parque de 2013 se interessam pelo local, principalmente por seus atrativos naturais. Outro motivo encontrado na pesquisa foram os pedidos de licença pelos funcionários da COSANPA para morarem nas proximidades, a densidade demográfica do bairro acompanha o processo de expansão urbana da região metropolitana de Belém (UTINGA, 2013).

No estudo elaborado para plano de manejo é demostrado que a população residente do entorno do parque é em sua maioria habitante a mais de vinte anos e que na sua maioria são provenientes do mesmo bairro ou seja é uma população relativamente consolidada no local, muitos são provenientes da onda migratória da década de 70 e 80, quando serão instalados na Amazônia paraense vários projetos minero/metalúrgicos (BECKER, 2001), fortalecendo o serro de serviços de Belém demandando por mais mão de obra especializada e por mão de obra barata.

A origem da maioria $(56,8 \%)$ das famílias entrevistadas é o próprio bairro em que residem, enquanto $43,2 \%$ provêm de outros locais. A maior parte (52\%) dessas famílias reside há mais de vinte anos no mesmo local: $21 \%$ delas possuem um tempo de permanência entre vinte e trinta anos; $18 \%$ moram no local entre trinta e um e quarenta anos; e $13 \%$ estão lá há mais de quarenta anos. Apenas $17 \%$ das famílias residem há menos de cinco anos no entorno do parque. (UTINGA, 2013 p. 175).

Do ponto de vista sócio- Ambiental o bairro apresenta trechos vinculados ao divisor de águas que é a Avenida Almirante Barroso, principal via de escoamento rodoviário de Belém que liga a cidade a BR- 
316, e trechos com topografia mais baixa vinculada vales, canais fluviais urbanos e várzeas (Figura 03).

Na parte noroeste do bairro dois setores chamaram atenção, a Passagem Ana Deusa e a Passagem Coronel Moisés conhecidos respectivamente por "Buraco Fundo" e "Buraco quente" nomes atribuídos considerando o grau de periculosidade e a geomorfologia do local através de suas vertentes côncavas. A espacialidade da criminalidade passa pela ausência do estado nas comunidades, onde suas politicas assistem as classes B e A com a tentativa de tornar a área de preservação ambiental em um espaço turístico.

Parte do bairro do Curió -Utinga foi ocupado de forma desordenada, e muitos terrenos de várzea foram aterrados, sendo subdivididos em lotes de tamanhos variados, associado a ocupação irregular das vertentes, e ocupação integral da planície de inundação, assim os igarapés que foram gradativamente sendo transformados em canais para lançamento de esgoto, não possuindo assistência adequada do estado que abre margens para a logística da criminalidade e tráfico de drogas.

\section{4 -O PARQUE COMO LUGAR}

Nos primeiros anos de funcionamento do Parque a população participava ativamente das ações de proteção e limpeza dos mananciais, por meio de atividades remuneradas, sendo essa população remanescente do interior do estado do Pará e nordestinos. Um aspecto evidente durante a pesquisa é a relação estabelecida entre a população de entorno e a prestação de serviços a Cosanpa e, por isso, atuavam ativamente no Parque, a fim de garantir a integridade dos mananciais Bolonha e Água Preta.

Figura 3: Expansão Urbana no entorno e Restruturação do PEUt

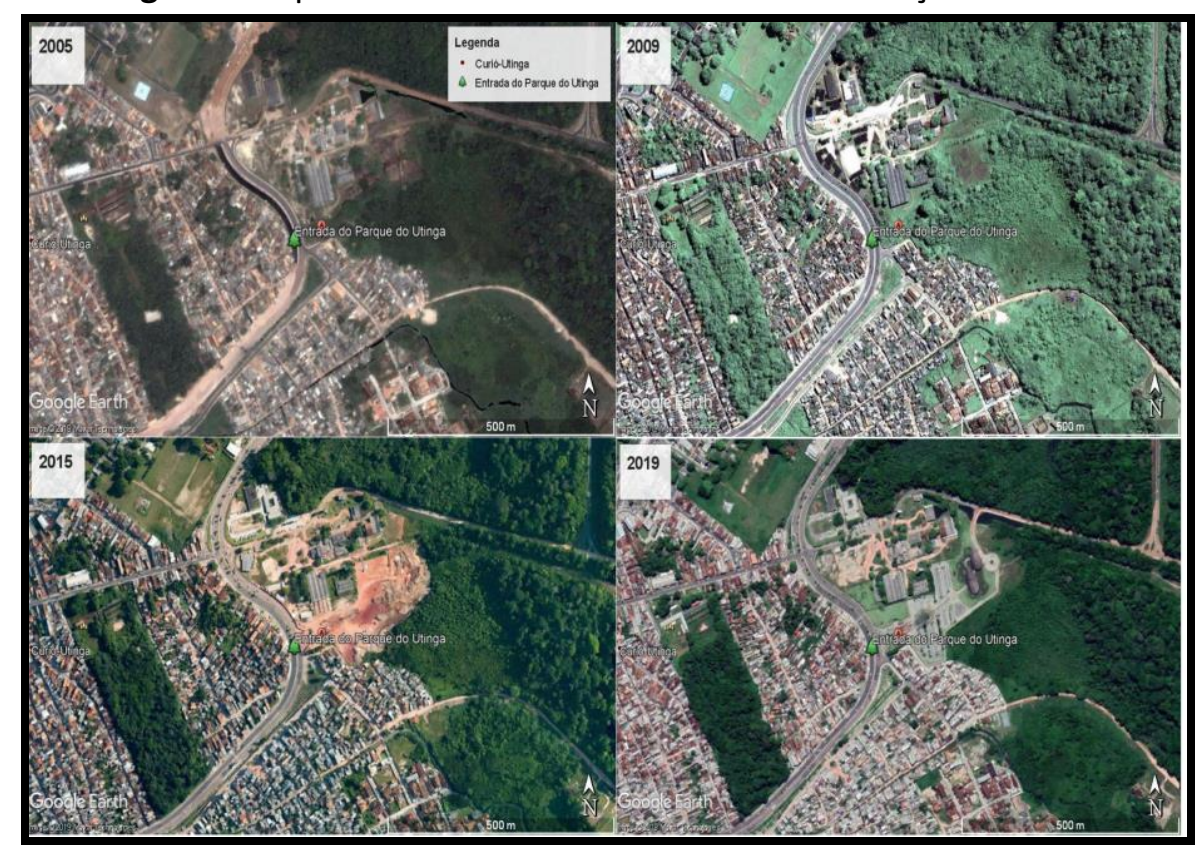

Fonte: Google Earth, Elaboração: SALES, 2019. 


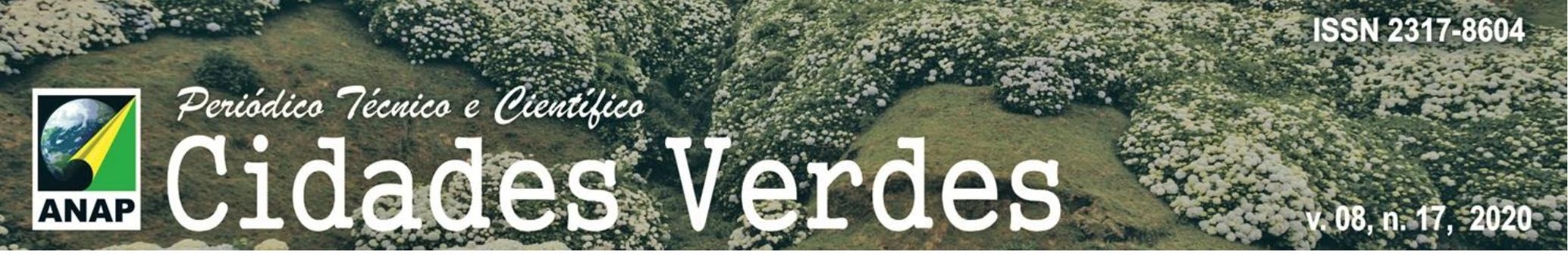

A famílias afirmam que na época que morava próximo ao lago Bolonha, gradativamente foram retirados e passaram a residir em frente ao Parque. Destaca-se que observavam ações da Cosanpa no sentido de se modernizar e expandir com injeção de investimento no século XX, porém, no século XXI ressaltam o sucateamento e precarização da Empresa, pelo tipo de serviço oferecido.

Outras atividades realizadas pelos que não eram funcionários da Companhia, mas por moradores locais era coleta de frutas regionais no início da manhã e final de tarde como Muruci (Byrsonima crassifolia), Taperebá (Spondias mombin L), Jaca (Artocarpus heterophyllus), e Jambo (Syzygium), mantendo uma relação de afetividade com o Parque, esse momento integrava a família, pois, as mulheres levavam seus filhos para caminhar pelo parque. Lembrar que antes transformação do Parque em PEUt era apenas proteção dos mananciais assim a população usava a área como extensão de seus quintais, para passeios, caminhadas, coleta de água manual e passarinhadas ${ }^{2}$.

Das inúmeras consequências para o Parque e sua relação com a comunidade local está a valorização do mesmo por meio do turismo; com gerenciamento do Parque por organização social, e inserção de empresas de oferecem uma série de serviços como Amazônia Aventura responsável por trilhas especificas interior do Parque e turismo de natureza e atividades como o Rapel (Figura 4) e tirolesa, além de empresas responsáveis por aluguel de bicicletas e, que convivem paradoxalmente com um lago recoberta por macrófitas, indicador de eutrofização de lagos e de antigas estruturas de captação de água da Cosanpa (Figura 4).

Dos impactos destaca-se o aumento do fluxo de pessoas desde a inauguração do novo Parque, em função de campanha publicitaria realizada pelo estado em canal de televisão aberta, que movimentou a economia do bairro, e os moradores começaram a desempenhar atividades informais como vendas água mineral, atividade deflanelinha ${ }^{3}$, porém, a presença de ambulantes na entrada do parque foi proibida, dificultando relação de proximidade e afetividade dos moradores com o parque.

\footnotetext{
2 Era comum na época utilização da área para passeio de pássaros criado em cativeiro, são levados para interagir com ambiente e outros pássaros por meio do canto, e para o dono coletar possíveis alimentos para as aves. Aves da espécie Curió eram comuns;

${ }^{3}$ Termo atribuído a pessoas que fazem vigilância informal a automóveis estacionados nas vias públicas, a pesar do mesmo serviço está sendo ofertado no interior do Parque
} 
Figura 4: Contradições do PEUt: (a) Projeto paisagístico atrativo na entrada do parque; (b) atividades terceirizadas no interior do PEUt como turismo de natureza; (c) Proliferação de macrofitas sob a lamina d'água do lago Bolonha; (d) antigas estruturas de captação de água da Cosanpa do século passado.

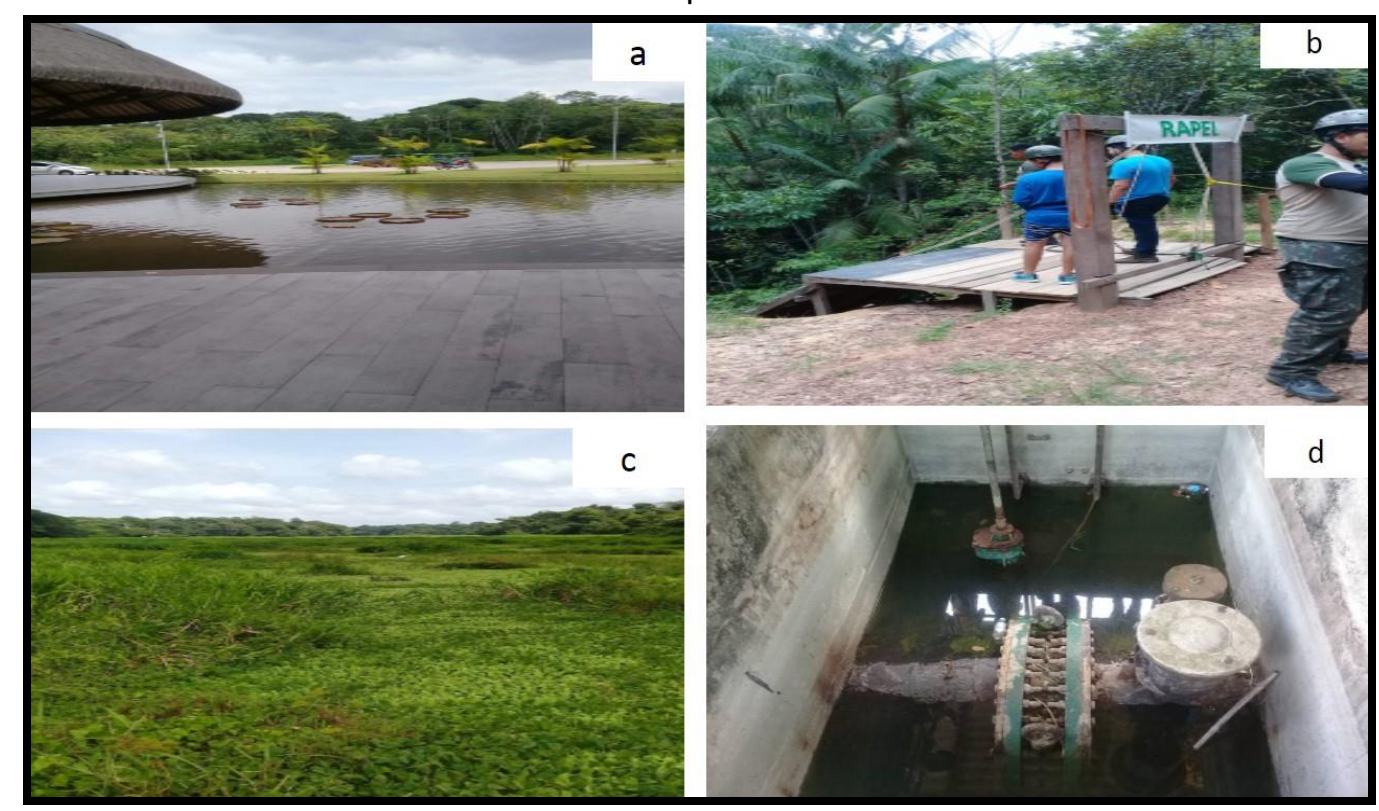

Fonte: SALES, 2019.

Ao longo do tempo a atuação "efetiva" do governo associadas a nova política administrativa do parque foram se transformando e a relação entre parque versus população ganhou outro significado. Nas entrevistas, parte dos moradores declararam que deixaram de frequentar o parque a partir da última reforma, três anos atrás, constituindo-se as maiores transformações ocorridas na área de preservação ambiental com a mudança de estruturas e de política de gestão, direcionadas para um grupo seleto de pessoas, no caso com maior poder aquisitivo, percebido no trabalho de campo são classe A e B, empresários, funcionários, públicos, professores e estudantes em caso de visita.

As estruturas do parque de certa forma pressionaram a população do entorno, passando pelo desmatamento de parte da área verde para a construção das novas estruturas, para mitigar tal ação o governo do estado passou a posse de terra para os moradores da Passagem Arara, localizada ao lado das novas estruturas do parque (ver figura 5).

As constantes transformações no entorno do Parque Estadual do Utinga passam pelas ações dos atores antrópicos ${ }^{4}$. Dentre as entrevistas o que chama a atenção é a perda afetividade dos moradores do bairro do Curió-Utinga em relação ao parque com as constantes modificações do seu modelo de gestão e das estruturas físicas, contrariando o discurso de inclusão dos mesmos.

\footnotetext{
${ }^{4}$ Passando pela esfera social (população residente no local) e política (atuação do Estado);
} 
Figura 5: (a) Entrevista com morador e antigo funcionário do Parque; (a) Declive acentuado com vertente íngremes ocupadas por moradores no bairro Curió-Utinga; (c) Pressão da População do Entorno nas Estruturas do Parque, visível por meio de um amontoado de casas separadas do parque apenas por uma grade; (d) Distribuição de água no bairro realizada por tubos obsoletos sujeitos a

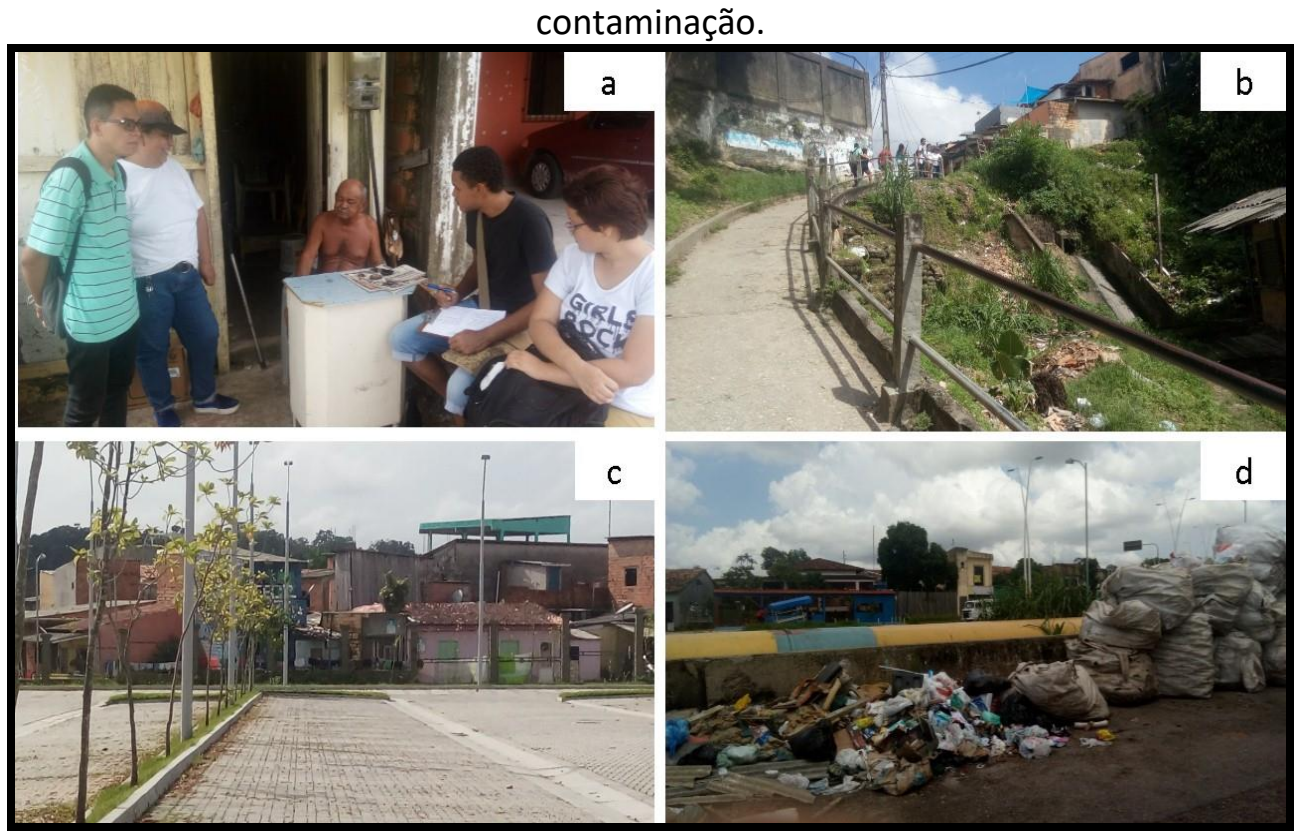

Fonte: SALES, 2019

As dinâmicas identificadas atualmente passam pela desvalorização do patrimônio cultural e de certa forma ambiental em que o parque se notabilizou durante sua trajetória. Os moradores do entorno, em sua maioria residem na área desde as primeiras instalações do parque, período onde a esta população detinha papel direto no desenvolvimento de tarefas no parque. Porém, no período atual, por conta dos novos usos identificados no parque, é notável a perda do valor simbólico dos moradores com o mesmo.

\section{5- PRESSÕES SÓCIOESPACIAIS NO ENTORNO DO PARQUE ESTADUAL DO UTINGA}

A análise da área externa no Parque Estadual do Utinga (PEUt), percebemos um número significativo de diferenças territoriais no bairro, nas quais ocorrem divergências principalmente no que tange as dinâmicas internas e as reivindicações da população local diante dos problemas de falta de água nas residências e também com de segurança instável do local.

Segundo relatos que obtivemos no campo, foi interessante perceber uma média significativa de pessoas que vivem no bairro e nunca sequer ingressaram ao Parque. Tal fator enfatiza a questão do marketing urbano e o urbanismo espetáculo exposto no trabalho de Sánchez (1997), no qual podemos através desses conceitos, explicar a grande divulgação midiática da reabertura do parque e os números elevados de visitas que o PEUt teve durante o seus primeiros meses depois da reinauguração, mas que foram revitalizações destinadas para a elite local e não para os moradores do bairro.

Essa forma de empreendimento urbano utilizada no parque é criticada por parte dos moradores por estabelecer uma gestão com uma área de pouco uso para os habitantes do bairro. Isso enaltece 
Figura 6: Pontos de alagamentos na Avenida João Paulo II.

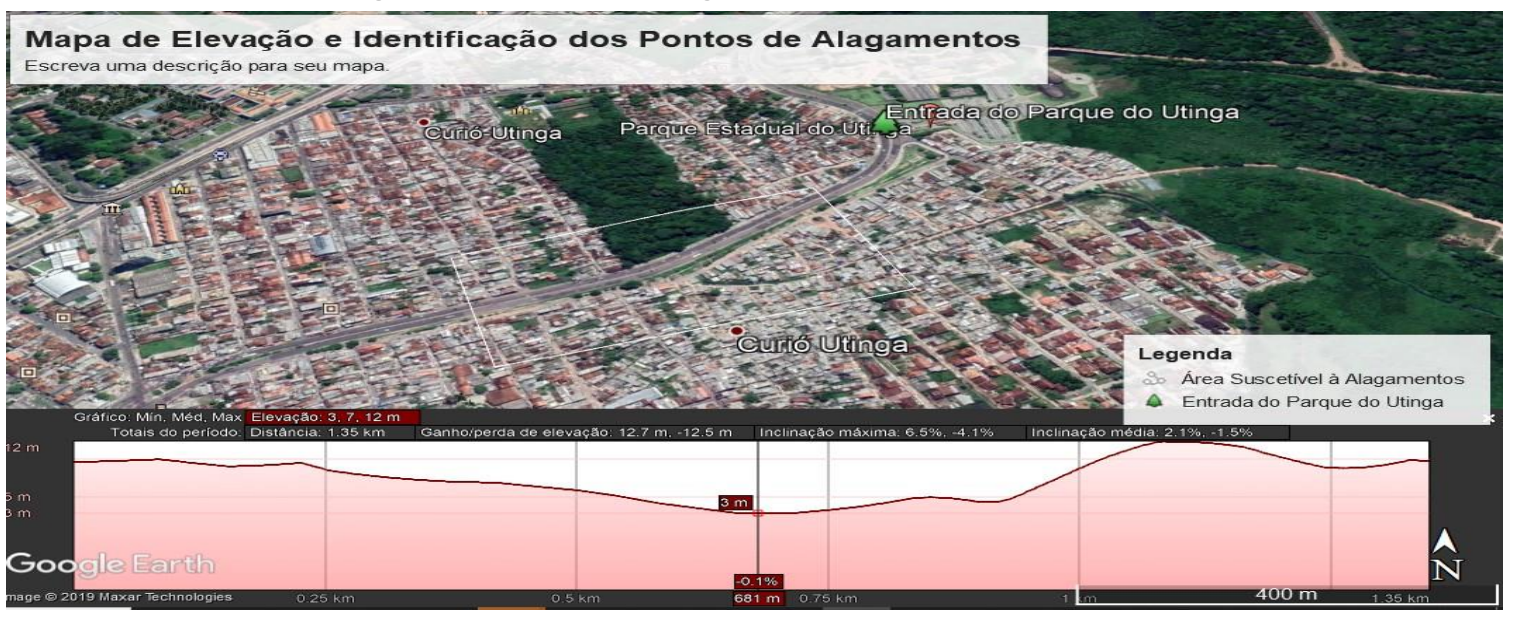

Fonte: Google Earth, Elaboração: SALES, 2019.

No que se trata da questão do abastecimento de água no bairro do Curió-Utinga foram constatadas que o abastecimento é falho; ocorre falta de água constante no bairro além da questão da qualidade hídrica. Verifica-se em $100 \%$ dos depoimentos dos moradores, que a água encanada é de baixa qualidade com uma "coloração amarelada".

Figura 7: Forte chuva inunda trechos da Grande Belém nesta tarde de quarta-feira" demonstrando graves alagamentos na Avenida João Paulo II

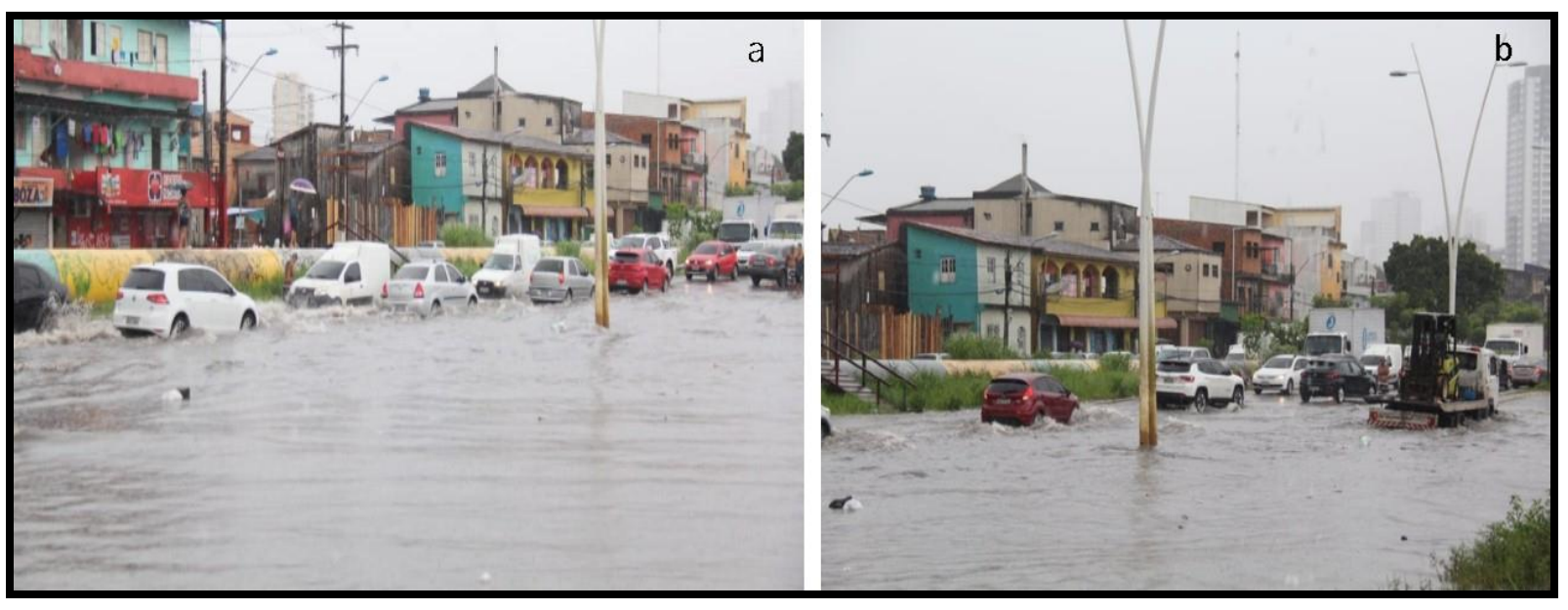

Fonte: O LIBERAL, 2019

A tubulação que transporta água do parque para os demais setores da cidade corta o bairro no setor sul, o que chama atenção é a exposição da tubulação e a presença de grande quantidade de lixo ao redor (ver figura 1), ou seja, expondo a água ao risco de contaminação, fatores que acometem os moradores a utilizarem água mineral e/ou filtrada.

\section{5 - CONCLUSÃO}

Atualmente a relação dos morados com o parque é voltado para o viés de localização, a maioria dos entrevistados não frequentam mais o parque devido a refuncionalização do parque, voltado para 


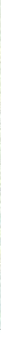

atividades de pessoas com o maior poder aquisitivo, caso esse se exemplifica no valor dos serviços terceirizados do parque como o aluguel de bicicletas, rapel, tirolesa e a cafeteria à preços de shoppings centers.

O que de fato interfere na dinâmica ambiental e no desenvolvimento social é a ação do estado acerca das politicas tomadas a partir de um conjunto de estratégias que assistem seus próprios interesses. De fato existe uma pressão antropogênica que interfere diretamente no desenvolvimento do meio de vida ecossistêmica que abrangem as unidades de conservações, assim como também, deve-se considerar o motivo pelo qual as populações vizinhas ao PEUt instalaram-se no local e a partir de qual período.

As dinâmicas sociais estão diretamente ligadas as políticas de preservação ambiental através de estratégias inclusivas do ponto do vista ambiental, porém, o estado acaba pressionando a população do entorno e invisibilizando a mesma através das políticas de (des)inclusão ${ }^{5}$ e assim modificando a dinâmica social/populacional resultando em moradias em áreas de vazes no entorno do PEUt.

\section{REFERÊNCIAS}

ALMEIDA, Conceição Maria Rocha. As águas e a cidade de Belém do Pará: história, natureza e cultura material no século XIX PUC, São Paulo 2010

BAHIA, Vânia Eunice et al. Avaliação hidrogeoquímica dos recursos hídricos na área de abrangência do parque estadual do utinga - Belém (PA). XVI Congresso Brasileiro de Águas Subterrâneas e XVII Encontro Nacional de Perfuradores de Poços, Disponível em:<

https://aguassubterraneas.abas.org/asubterraneas/article/view/22928> Acesso em 16 Set. 2019.

BERTHA K. BECKER. Revisão das políticas de ocupação da Amazônia: é possível identificar modelos para projetar cenários? Parcerias estratégicas, n. 12, p. 136 -- 159, set 2001

GOMES, Marcos Antônio Silvestre PARQUES URBANOS, POLÍTICAS PÚBLICAS E SUSTENTABILIDADE. Mercator, Fortaleza, v. 13, n. 2, p. 79-90, mai/ago. 2014

CASTRO, Iná Elias de. Geografia e Política: território, escalas de ação e instituições. Rio de Janeiro: Bertrand Brasil, 2005.

CRUZ, E. As águas de Belém: sistemas de abastecimento usados na capital desde os tempos imemoriais. Oficina da Revista de Veterinária, Belém, 1944.

Plano Geral das Obras para Remodelação dos Serviços de Abastecimento de Água de Belém. As Obras Públicas do Estado do Pará. Belém: Governo do Estado do Pará: Secretaria de Estado Viação e Obras Públicas, 1967. p. 375-388.

FERREIRA, L. C. Dimensões humanas da biodiversidade: mudanças sociais e conflitos em torno de área protegidas no Vale do Ribeira, SP. In: Ambiente e Sociedade. Campinas, v. VII, n.1, p. 47-66, jan/jun. 2004.

MMA. Áreas Protegidas. Gestão Participativa do SNUC. Brasília: Ministério do Meio Ambiente, 2004.

\footnotetext{
${ }^{5}$ No momento em que o estado cria politicas ditas ambientais para o PEUt, o mesmo acaba ignorando a população do entorno que passa a sofrer com as consequências do descaso.
} 


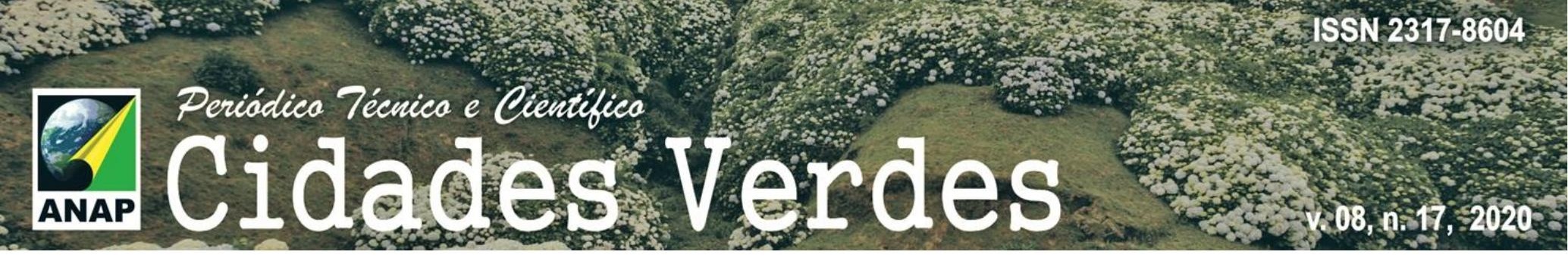

O LIBERAL, Jornal. Forte chuva inunda trechos da Grande Belém nesta tarde de quarta-feira" demonstrando graves alagamentos na Avenida João Paulo II. Acesso em 03 Mar 2019. Disponível em:

<https://www.oliberal.com/belem/forte-chuva-inunda-trechos-da-grande-belém-nesta-tarde-de-quarta-feira1.6208>

PARÁ. Secretaria de Estado de Meio Ambiente. Resumo Executivo do Plano de Manejo do Parque Estadual do Utinga. Secretaria de Estado de Meio Ambiente. Belém: SEMA; Belém: Imazon, 2013.

SANCHEZ, F. Cidade Espetáculo: política, planejamento e city marketing. Editora Palavra, 1997.

SOUSA, T. C. S; BORDALO. Os impactos socioambientais nos lagos bolonha e água preta: 0 processo de degradação na reserva do Utinga, localizada em Belém do Pará. VII Congresso Brasileiro de Geógrafos. Disponível em:< http://www.cbg2014.agb.org.br/resources/anais/1/1404148620_ARQUIVO_THAYSSASOUSAARTIGOCBG.pdf> Acesso em 10 Out 2018.

TUAN, Yi-Fu. Topofilia: um estudo da percepção, atitudes e valores do meio ambiente. Trad. Lívia de Oliveira. Londrina: Eduel, 2012.

TUAN, Yi-Fu. Espaço e Lugar. A perspectiva da experiência. São Paulo. Difel. 1983.249p.

UNESCO BRASIL, IPHAN. Gestão do Patrimônio Mundial natural. - Brasília: UNESCO Brasil, IPHAN, 2016. 107p.

SANTOS, Milton. A Natureza do Espaço: Técnica, Razão e Emoção. 3ạ Edição. São Paulo: Edusp (Editora da USP), 2003. 